\title{
Warum stört in den Magen gelangende Galle den Verdauungsprocess?
}

Von

\section{R. Rurkart.}

Im physiologischen Institute zu Bonn wurden im Laufe des Wintersemesters über den Einfluss der Galle auf die Magenverdaung mehrere Versuche angestellt, deren Resultate ich hier mittheile. Zur Herstellung der bei allen angeführten Versuchen angewandten Verdauungsflïssigkeit benutzte ich Magen vom Schwein. Die Schleimhaut desselben wurde mit einem stumpfen Messer abgeschabt, der gewonnene röthliche Schleim mit 0,3prozentiger Salzsäure (250-350 Cc, auf 1 Magen) versetzt und $1 \frac{1 / 2}{1}-2$ Stunden im Brütofen bei einer Temperatur von $35^{\circ}-38^{\circ} \mathrm{C}$. digerirt; dann wurde die Flüssigkeit filtrirt und das Filtrat als Verdauungssaft gebraucht.

Die Gallensalzlösung, welche ich bei meinen Versuchen anwandte, stellte ich auf folgende Weise dar: ich dampfte mit Thierkohle versetzte Rindergalle im Wasserbade bis zur vollständigen Trockenheit ein, zog aus dem trocknen Rückstande die Gallensalze mit absolutem Alkohol aus, filtrirte die erhaltene Lösung, fällte aus dem Filtrat die Gallensalze mit absolutem Aether, trocknete die so erhaltenen Salze bei einer Temperatur bis zu $80^{\circ} \mathrm{C}$. und löste dieselben dann in Wasser.

Die Verdauungsversuche wurden im Brütofen bei einer Temperatur, welche zwischen $35^{\circ}$ und $40^{\circ} \mathrm{C}$. schwankte, angestellt.

1 ter Versuch. 50 Cc. Magensaft versetzte ich mit 25 Cc. 5 prozentiger Gallensalzlösung, wobei in der vorher vollkommen klaren Verdauungsflüssigkeit eine milchige Trübung entstand. Diese $75 \mathrm{Cc}$. Magensaft und Gallensalzlösung verblieben 16 Stunden in der Brütemaschine, nach welcher Zeit von einer verdauenden Kraft der Flüssigkeit an dem beigefügten Eiweisswürfel nichts bemerkt werden konnte; die vor dem Einstellen in den Brütofen bestehende milchige Trübung aber war jetzt verschwunden, die Flüssigkeit erschien zwar noch nicht vollkommen klar, doch hatte sich auf dem Boden des Becherglases 
ein feiner Schlamm abgesetzt. Die Flüssigkeit wurde (mit Bodensatz) auf ein Filter gebracht, der auf dem Filter bleibende Rückstand getrocknet, mit 80prozentigem Alkohol ausgewaschen, wobei Gallensäuren in Lösung übergingen, der noch bleibende Rückstand abermals getrocknet und dann mit 50 Cc. 0,3 prozentiger Salzsäure, die ich bis zu $30^{\circ} \mathrm{C}$. erwärmte, behandelt; hierbei löste sich der Rückstand zum grössten Theil in der Salzsäure. Diese Lösung mit einem Eiweisswürfel versehen in den Brütofen gestellt, zeigte entschieden verdauende Kraft.

2ter Versuch. Hierzu wurden zwei Mischungen ( $a$ und $b$ ) von folgender Zusammensetzung gewählt.

a) $100 \mathrm{Cc}$. Magensaft; $40 \mathrm{Cc}$. 9prozentiger Gallensalzlösung; Eiweisswürfel,

b) 50 Cc. desselben Magensaftes; Eiweisswürfel.

Nach sechszehnstündigem Stehen im Brütofen war in a) der Eiweisswürfel noch nicht angegriffen, während der in b) vollständig sich gelöst hatte.

Die a) Flüssigkeit wurde wie im vorigen Versuche aut ein Filter gebracht; und das Filtrat in 6 Portionen getheilt, die mit verschiedenen Quantitäten CIH versetzt wurden, um darzuthun, dass die Verringerung der Magensäure durch Galle nicht die Ursache der störenden Wirkung sei.

\begin{tabular}{|c|c|c|}
\hline \multicolumn{3}{|c|}{$\begin{array}{c}\text { Menge des Menge der zugesetzten! } \\
\text { Filtrats }\end{array}$} \\
\hline$\alpha 25 \mathrm{Cc}$ & & \\
\hline$\beta 25 \mathrm{Cc}$. & $0,8 \mathrm{CC}$. & Keine der Flüssigkeiten hatte \\
\hline$\gamma 25 \mathrm{Cc}$. & 0,1 & während eines 16stïndigen Stehens \\
\hline$d 16 \mathrm{Cc}$ & 0,2 & gebenen Eiweisswürfel angegriffen. \\
\hline$\varepsilon 16 \mathrm{Cc}$ & 0,4 & \\
\hline$\zeta 16 \mathrm{Cc}$ & 0,6 & \\
\hline
\end{tabular}

Den auf dem Filter gebliebenen Rückstand trocknete ich wie im 1ten Versuche über Schwefelsäure, wusch ihn mit 80prozentigem Alkohol aus, trocknete wieder und behandelte ihn zuletzt mit verdünnter Salzsäure, um dann mit dieser Flüssigkeit Versuch A und B anzustellen.

A) mit 50 Cc. 0,3 prozentiger Salzsäure von $9^{\circ} \mathrm{C}$. Temperatur.

B) mit 50 Cc. 0,3 prozentiger Salzsäure von $30^{\circ} \mathrm{C}$. Temperatur. 
210 Warum stört in den Magen gelangende Galle den Verdauungsprocess?

$A$ und $B$ wurden gleichzeitig mit einem Gemisch $C$ aus $50 \mathrm{CC}$. 0,3 prozentiger $\mathrm{ClH}$, dem auch ein Eiweisswürfel zugesetzt war, in den Brütofen gestellt, in welchem sie 18 Stunden verblieben. Nach dieser Zeit hatte $A$ und $B$ den zugegebenen Eiweisswürfel vollständig aufgelöst, während der Eiweisswürfel in $C$ noch unversehrt war. (Alle drei Eiweisswürfel waren gleich gross.)

Aus diesen Versuchen geht hervor, dass das Pepsin durch den bei Zusatz von Galle zum sauren Magensaft entstehenden Niederschlag der Glykocholsäure mechanisch niedergerissen wird. 'Trennt man das Pepsin von jenem Niederschlag und führt dasselbe wieder in saure Lösung, so erhält es seine verdauende Kraft zurück.

Um aber eine gewisse Quantität Magensaft verdauungsunfähig zu machen, d. h. also, um alles Pepsin zu fällen, ist immer eine verhältnissmässig ganz ansehnliche Quantität von Galle nothwendig, wie dies mehrere von mir angestellte Versuche zeigen:

\begin{tabular}{|c|c|c|c|c|}
\hline $\begin{array}{l}\text { Menge des } \\
\text { ilagensaftes }\end{array}$ & $\begin{array}{l}\text { Menge der } \\
\text { uugesetrten } \\
5 \text { Procent } \\
\text { Gallaufl. }\end{array}$ & $\begin{array}{l}\text { Gewicht } \\
\text { des frischen } \\
\text { Eiweissw. }\end{array}$ & $\left|\begin{array}{c}\text { Gewicht des- } \\
\text { selben, aber } \\
\text { getrockneten } \\
\text { Eiweissw. }\end{array}\right|$ & $\begin{array}{l}\text { Gewicht des getrocknetn Eiweissrickstandes } \\
\text { nach einem } 19 \text { stindigen Stehen in der lirüte- } \\
\text { maschine. }\end{array}$ \\
\hline a. 40 & & 1,83 & 0,43 & $\begin{array}{c}\text { Der Eiweissw. war vollständig } \\
\text { aufgelöst. }\end{array}$ \\
\hline b. $50 \mathrm{Cc}$. & $1 \mathrm{Cc}$. & 2,09 & 0,49 & $\begin{array}{l}\text { Der Eiweissw. war bis auf einen } \\
\text { minimalen Rest aufgelöst. }\end{array}$ \\
\hline c. $50 \mathrm{Ce}$. & $2 \mathrm{Cc}$. & 3,08 & 0,72 & $\begin{array}{c}0,15 ; 4 / 5 \text { des Eiweissw. waren } \\
\text { also verdaut. }\end{array}$ \\
\hline d. $50 \mathrm{Cc}$ & $3 \mathrm{Cc}$. & 2,48 & 0,58 & $\begin{array}{c}0,13 ; 7 / 10 \text { des Eiweissw. waren } \\
\text { verdaut. }\end{array}$ \\
\hline
\end{tabular}

Alle Versuche wurden auf Veranlassung des Herrn Prof. P fluger angestellt; demselben für seinen Rath und thätige Unterstützung hiermit meinen aufrichtigen Dank. 